Int. J. Odontostomat., 6(3):285-289, 2012.

\title{
Esthesioneuroblastoma: a Case Report and Review of the Literature
}

\author{
Estesioneuroblastoma: Reporte de un Caso y Revisión de la Literatura
}

Ilson Sepúlveda*; Álvaro Herrera*; Carolina Delgado*; Enrique Platin ${ }^{* * *}$ \& Pablo Rosel ${ }^{* * *}$

SEPÚLVEDA, I.; HERRERA, A.; DELGADO, C.; PLATIN, E. \& ROSEL, P. Esthesioneuroblastoma: a case report and review of the literature. Int. J. Odontostomat., 6(3):285-289, 2012.

ABSTRACT: We report on a patient who presented to our clinic with a one-year history of diplopia in the left eye, epistaxis for one month and pain in the occipital area of the head. A biopsy of the area was performed and the lesion was diagnosed as Esthesioneuroblastoma also known olfactory neuroblastoma. Due to the size of the tumor and involvement of the vital intracranial structures it was decided to prescribe a palliative care program and palliative radiotherapy.

KEY WORDS: esthesioneuroblastoma, CT, MRI, tumor, sinonasal.

\section{INTRODUCTION}

Esthesioneuroblastoma (ENB) was first described by Berger and colleagues in 1924, they named it esthésioneuroépithéliome olfactif. This tumor was later given various names due to the lack of knowledge of its histological origin. However, only two terms have been used in recent publications, ENB and olfactory neuroblastoma (Dulguerov et al., 2001; Hwang et al., 2003; Lin et al., 2009; Yu et al., 2009).

This is a rare neoplasm of neuroectodermal origin that arises from olfactory epithelium in the upper nasal cavity at the level of the cribriform plate. It accounts for $3-6 \%$ of all intranasal tumors. The incidence peaks between the ages of 11 and 20 years of age and again between the $50^{\text {th }}$ and $60^{\text {th }}$ decade of life (Palacios \& Valvassori, 1998; Hwang et al.; Tamase et al., 2004; Lin et al.; Ghaffar \& Salahuddin, 2005; Yu et al.; lliades et al., 2002; Thompson, 2009). The symptoms and signs are characterized by nasal obstruction, epistaxis, headache, hyposmia, exophthalmos, and diplopia (Tamase et al.; Ghaffar \& Salahuddin; Thompson).

The development of ENB beyond the region where the olfactory epithelium exists is extremely rare. Only nine cases have been reported as esthesioneuroblastoma outside the cribriform plate. They include five cases in the sellar region, 3 cases in the sphenoid sinus and one additional case in which the clinical details were unable to be confirmed. The etiology and pathogenesis of ENB is not fully understood. Herrold (1964) and Vollrath et al., (1986) induced ENB in the nasal cavity of hamsters by injecting nitrous derivatives. Other authors have proposed the possibility of a virus being responsible for its development, in particular the polyomavirus (Lin et al.).

Many genetic markers of neuroblastomas such as Ploidy status, oncogene amplification or Allelic loss, have been correlated to its clinical outcome. A subset of patients with neuroblastoma shows a predisposition for its development and this predisposition follows an Autosomal-Dominant pattern of inheritance (Brodeur, 2003).

These tumors have the potential to spread regionally. Neck metastasis can occur either early in the disease or many years later. Metastasis of cervical lymph nodes occurs in approximately $10 \%$ of cases. Haematogenous metastases are rare but may occur in bone, bone marrow, lung or skin at the time of relapse. Therefore, the possibility of a second tumor

* Oral, Maxillofacial-Head and Neck Radiologist. Ear, Head and Neck Cancer Committe, ENT Service, General Hospital of Concepcion. Professor of Oral and Maxillofacial Radiology, Finis Terrae University School of Dentistry, Santiago, Chile.

** Physician Pathologist, Pathology Department, Clinical Hospital of Concepción. School of Medicine, University of Concepción, Concepción, Chile.

*** Professor of Oral and Maxillofacial Radiology, School of Dentistry, University of North Carolina Chapel Hill, NC, USA.

${ }^{* * * *}$ Physician, ENT Program Resident, Clinical Hospital of Concepción. School of Medicine, University of Concepción, Concepción, Chile. 
must be considered in the differential diagnosis of patients with new or recurring symptoms especially after having been radiated for pituitary adenoma (Dulguerov et al.; Ghaffar \& Salahuddin; Chatterjee et al., 1997; Park et al., 2008; Casiano et al., 2001).

One of the most reliable histologic features is its lobular architecture. The circumscribed lobules or nests are made up of "primitive" neuroblastoma cells. They are usually located below an intact mucosa and in a vascularized fibrous stroma. The tumor cells are small, round and blue (Yu et al.; Thompson).

This tumor is staged using the Kadish et al., (1976) System. Stage A is limited to the nasal cavity, stage $B$ involves the paranasal sinuses, and in stage $C$ the tumor extends beyond the nose and paranasal sinuses as seen in our patient. Three types of direct intracranial extensions by ENB can be found on CT and MRI: cranio-orbital-nasal communicating ENB, cranio-nasal communicating ENB; and orbital-nasal communicating ENB. ENB exhibits no specific appearance on MRI and CT Imaging. The combined use of CT and MRI techniques is excellent in providing necessary information for treatment planning (Dulguerov et al.; Hwang et al.; Lin et al.; Park et al.; Yu et al.; Kurian et al., 2004).

Using a CT bone window, the tumor displays bone remodelling such as dilation of the nasal cavity causing bone destruction and is observed especially in the cribriform plate. A CT with intravenous contrast shows a homogenous enhanced mass. T1 weighted magnetic resonance imaging with gadolinium contrast shows marked enhancement. Cysts in the intracranial tumor margin, are highly suggestive of ENB (Palacios \& Valvassori; Lin et al.; Yu et al.; Thompson; Harnsberger et al., 2004).

The overall survival rate in patients with esthesioneuroblastoma has changed dramatically since Berger and Luc first described the disease in 1924 (Berger et al., 1924). Today, the standard treatment is external craniofacial resection followed by postoperative radiotherapy. Surgery along with adjuvant radiation therapy alone or in combination with chemotherapy (for recurrent or advanced disease) has improved the long-term survival rate for tumors previously considered inoperable. However, local recurrence rates are high and are reported to be between $58 \%$ and $62 \%$ (Dulguerov et al.; Tamase et al.; Ghaffar \& Salahuddin; Park et al.; Kurian et al.; Casiano et al.; lliades et al.).

\section{CASE REPORT}

We report on a 66 year old male patient with a history of hypertension and diabetes mellitus who was undergoing treatment for these conditions. The patient requested a consultation with the ENT service. He complained of having diplopia for one year, epistaxis for one month and a severe headache in the occipital region of the head.

A CT was performed revealing an expansive process involving the left maxillary, sphenoid, and ethmoid sinuses as well as the left frontal bones (Fig. 1). The lesion also involved the nasal septum and hard palate

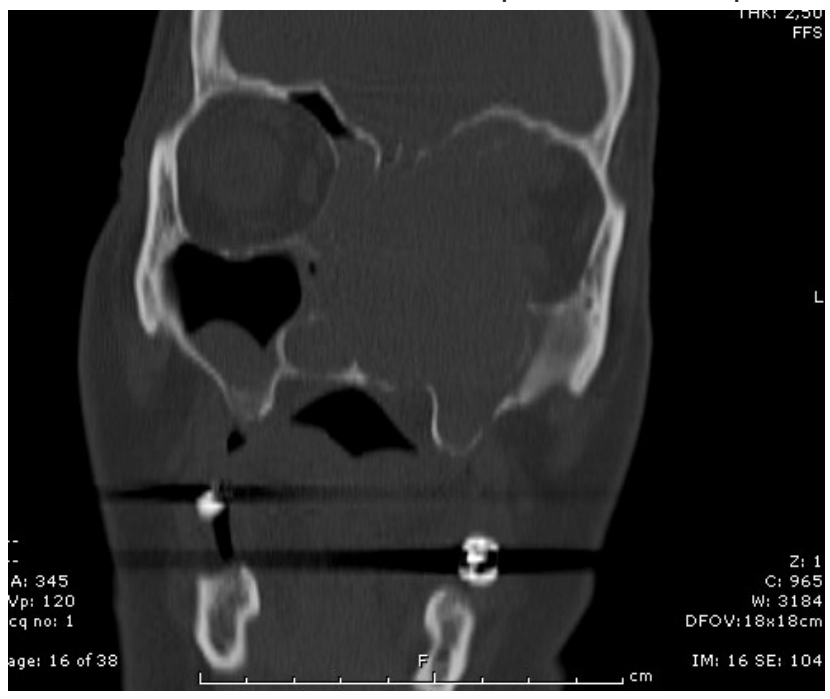

Fig. 1. CT bone window showing an expansile process with involvement of the paranasal sinuses.

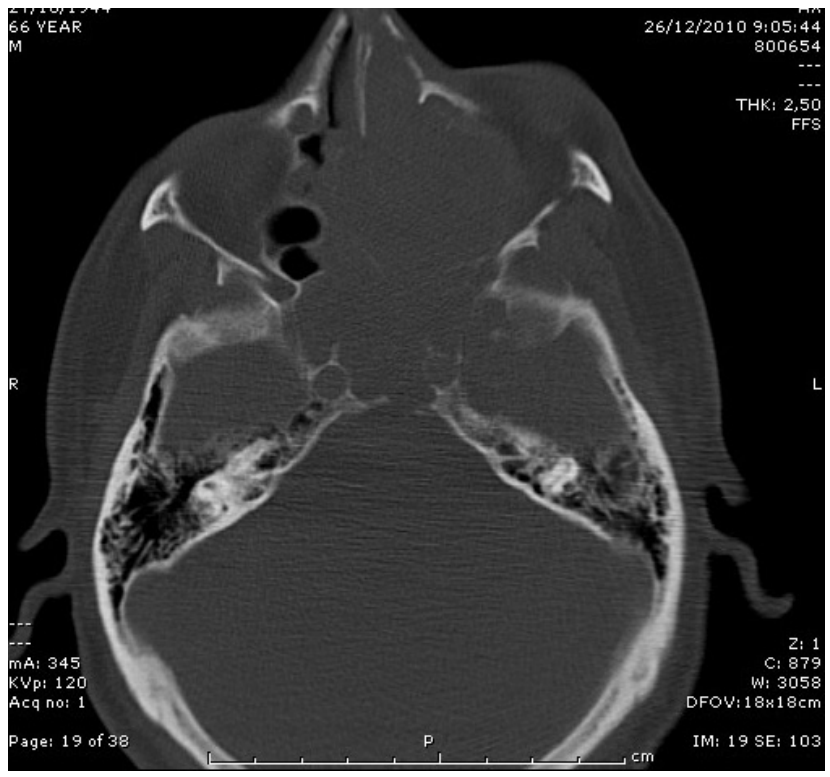

Fig. 2. CT bone window revealing an osteolytic lesion involving the medial wall of the left orbital cavity and displacement of the eyeball. 
extending to the nasal cavity and left orbit. The left eyeball was displaced anteriorly and laterally. Discontinuity was observed in the posterior wall of the left orbit and ipsilateral posterior wall of the sphenoid sinus with apparent intracranial involvement (Fig. 2).

The T1 MR sequence showed an expansive process of low signal extending into the left nasal cavity (Fig. 3). The T1, Fat Saturated Gadolinium sequence revealed a poorly enhancing lesion which has displaced the nasal septum to the right side and partially destroyed the medial wall of the left maxillary sinus and orbit. The lesion has caused destruction of the ethmoid cells and

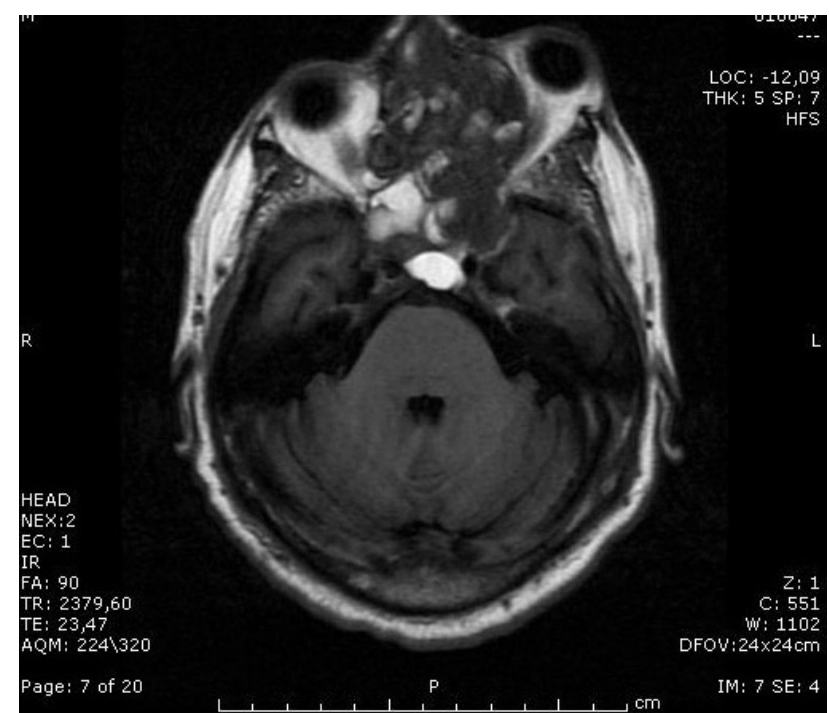

Fig. 3. MR T1 sequence. Low signal mass, compromising the intraconal fat; with lateral displacement of the left optical nerve suggestive of left temporal lobule infiltration.

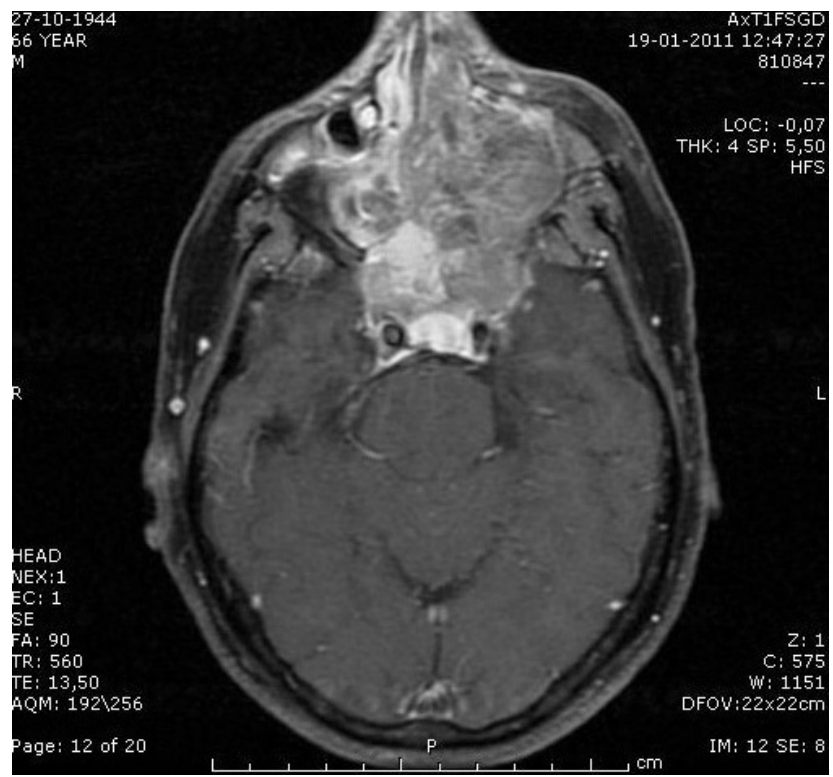

Fig.4. MR T1FSGD sequence. Infiltrative mass poorly enhancement. Posterior extension to left cavernous sinus. extends into the left cavernous sinus. Extracoronal invasion with involvement of the extrinsic muscles was observed (Fig. 4).

The T1FSGD coronal view, shows thinning of the floor of the left anterior skull base, which has been caused by either destruction or demineralization and there appears to be intradural invasion (Fig. 5). In the T2 sagittal sequence there is invasion of the left frontal sinus by an expansile process as well as secretions. Subsequent extension of the expansion revealed partial destruction of the left side of the sphenoid sinus, partially filled with secretions (Fig. 6).

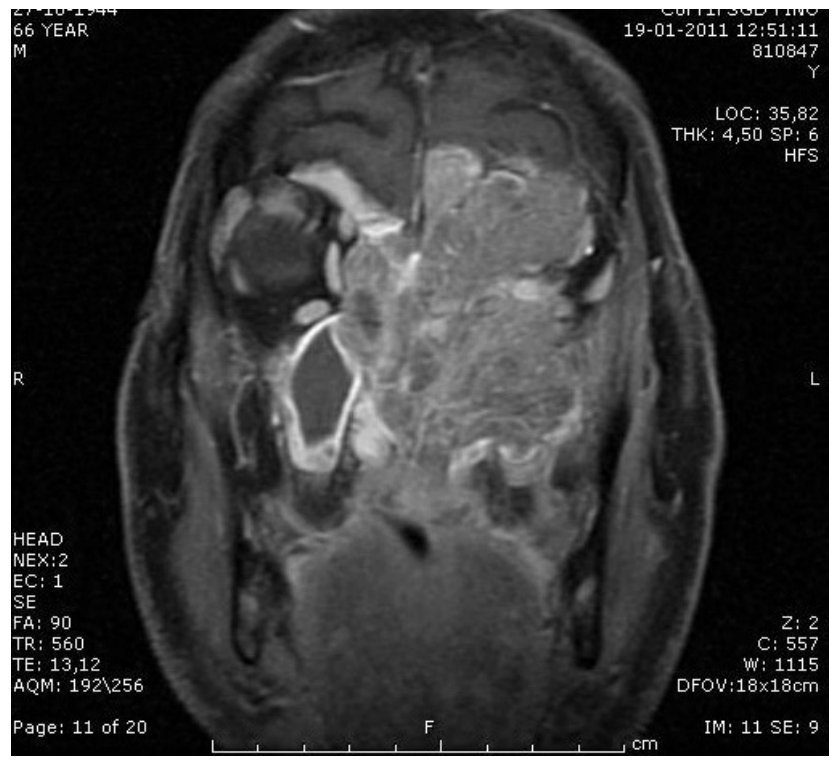

Fig 5. MR T1FSGD in coronal view. Apparent intradural invasion. Central necrotic or cystic degeneration areas. Involvement of hard palate.

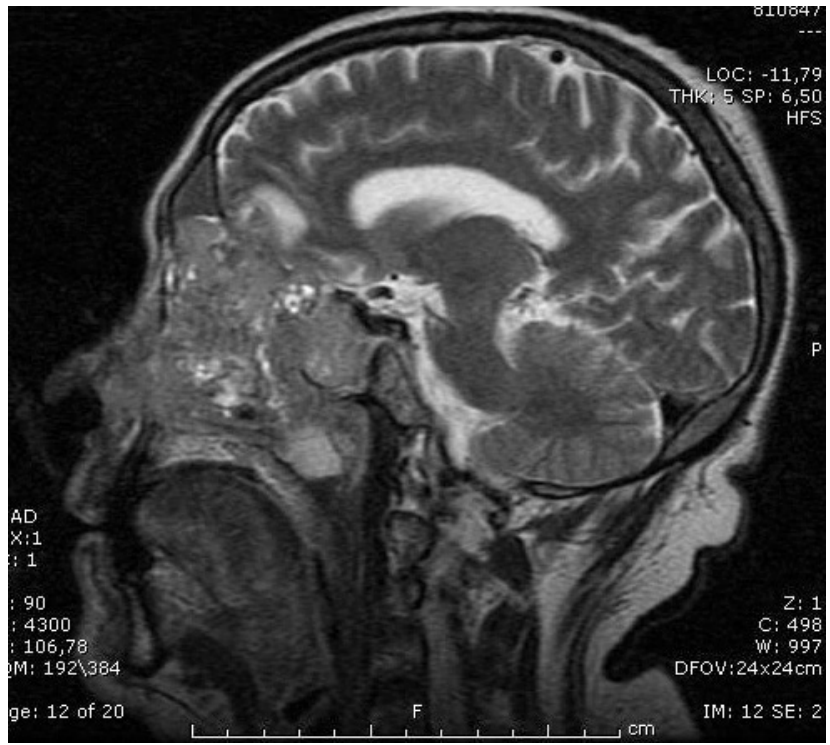

Fig. 6. MR T2 sequence. Partial occupation of the frontal and sphenoid sinuses with the neoplasm as well as secretions. 


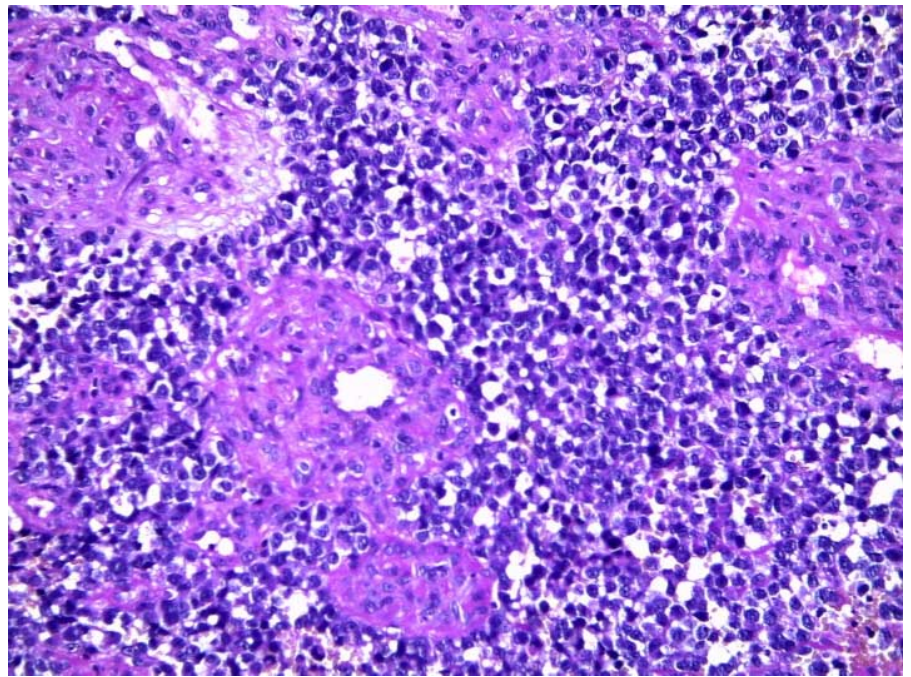

Fig. 7. Haematoxylin \& Eosin stain.

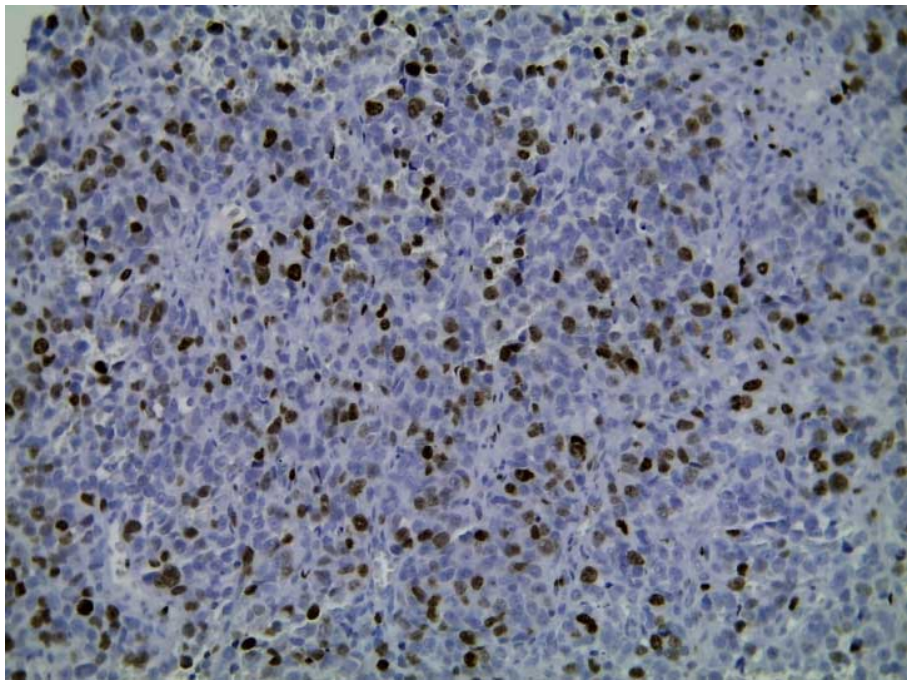

Fig. 8. Ki67 Stain positive.

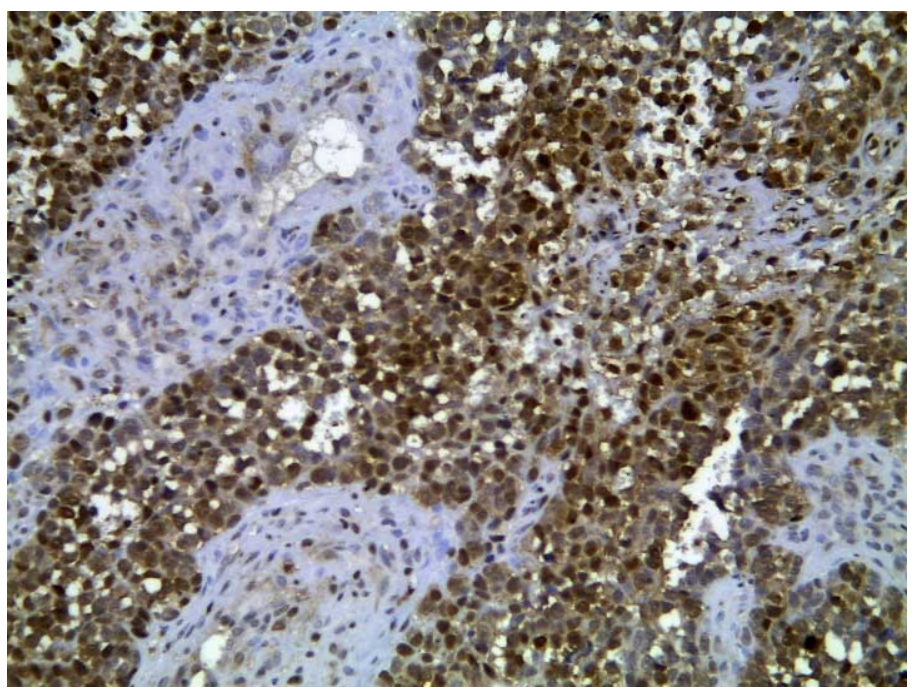

Fig. 9. Neuron Specific Enolase tintion positive.
Post $\mathrm{H}$ \& E staining (Fig.7) and immunohistochemical analysis with Ki67 (Fig. 8) and Neuron Specific Enolase (Fig. 9) revealed a neuroectodermic tumor of olfactory neuroblastoma type. The patient was evaluated by the head and neck cancer committee, where it was determined the tumor was inoperable. As a result the committee suggested palliative radiotherapy and pain management.

\section{CONCLUSION}

Esthesioneuroblastoma is a rare neoplasm of neuroectodermal origin that arises from olfactory epithelium in the upper nasal cavity at the level of the cribriform plate. It accounts for 3$6 \%$ of all intranasal tumors. The etiology and pathogenesis are poorly understood. These tumors have the potential for regional spread. Neck metastasis can occur either early in the disease process or many years later. Metastasis of cervical lymph nodes occurs in $10 \%$ of cases. One of the most reliable histologic features is its lobular architecture; the tumor cells are small, round and blue. The combined use of CT and MRI techniques is excellent in providing necessary information for treatment planning. This tumor has a high local recurrence rate in the range of $58 \%$ to $62 \%$.

SEPÚlVEDA, I.; HERRERA, A.; DELGADO, C.; PLATIN, E. \& ROSEL, P. Estesioneuroblastoma: reporte de un caso y revisión de la literatura. Int. J. Odontostomat., 6(3):285-289, 2012.

RESUMEN: Se presenta el caso de una paciente que acudió a nuestra consulta con historia de un año de diplopía en el ojo izquierdo, epistaxis durante un mes y dolor en la zona occipital de la cabeza. Se realizó una biopsia del área y la lesión fue diagnosticada como estesioneuroblastoma también conocido neuroblastoma olfatorio. Debido al tamaño del tumor y la participación de las estructuras vitales intracraneales, se decidió prescribir un programa de cuidados paliativos y radioterapia paliativa.

PALABRAS CLAVE: estesioneuroblastoma, CT, MRI, tumor, nasosinusal. 


\section{REFERENCES}

Berger, L.; Luc, G. \& Richard, D. L'esthesioneuroepitheliome olfactif. Bull. Assoc. Franç. Etude, 13:410-21, 1924.

Brodeur, G. M. Neuroblastoma: biological insights into a clinical enigma. Nat. Rev. Cancer, 3(3):203-16, 2003.

Casiano, R. R.; Numa, W. A. \& Falquez, A. M. Endoscopic resection of esthesioneuroblastoma. Am. J. Rhinol., 15(4):271-9, 2001.

Chatterjee, T.; Müller, M. F. \& Meier, B. Cardiac metastasis of an esthesioneuroblastoma. Heart, 77(1): 82-3, 1997.

Dulguerov, P.; Allal, A. S. \& Calcaterra, T. C. Esthesioneuroblastoma: a meta-analysis and review. Lancet Oncol., 2(11):683-90, 2001.

Eich, H. T.; Hero, B.; Staar, S.; Micke, O.; Seegenschmiedt, H.; Mattke, A.; Berthold, F. \& Müller, R. P. Multimodality therapy including radiotherapy and chemotherapy improves event-free survival in stage $C$ esthesioneuroblastoma. Strahlenther. Onkol., 179(4):233-40, 2003.

Ghaffar, S. \& Salahuddin, I. Olfactory neuroblastoma: a case report and review of the literature. Ear Nose Throat J., 84(3):150-2, 2005.

Harnsberger, H.; Hudgins, P.; Wiggins, R. \& Davidson, H. The 100 main Diagnostics in Head and Neck. Madrid, Elsevier, 2004. pp.168-71.

Herrold, K. M. Induction of olfactory neuroepithelial tumors in Syrian hamsters by diethylnitrosamine. Cancer, 17:11421, 1964.

Hwang, S. K.; Paek, S. H.; Kim, D. G.; Jeon, Y. K.; Chi, J. G. \& Jung, H. W. Olfactory neuroblastomas: survival rate and prognostic factor. J. Neurooncol., 59(3):217-26, 2002.

Iliades, T.; Printza, A.; Eleftheriades, N.; Georgios, K.; Psifidis, A. \& Thomas, Z. Olfactory neuroblastoma. A report of 3 cases. ORL J. Otorhinolaryngol. Relat. Spec., 64(6):4546, 2002.

Kadish, S.; Goodman, M. \& Wang, C. C. Olfactory neuroblastoma: a clinical analysis of 17 cases. Cancer, 37(3):1571-6, 1976.

Kurian, S.; Ertan, E.; Ducatman, B.; Crowell, E. B. \& Rassekh, C. Esthesioneuroblastoma in Maffucci's syndrome. Skeletal Radiol., 33(10):609-12, 2004.

Lin, J. H.; Tsai, D. H. \& Chiang, Y. H. A primary sellar esthesioneuroblastomas with unusual presentations: a case report and reviews of literatures. Pituitary, 12(1):70$5,2009$.

Palacios, E. \& Valvassori, G. Olfactory esthesioneuroblastoma (olfactory neuroblastoma/ olfactory neuroepithelioma). Ear Nose Throat J., 77(11): 890-1, 1998.

Park, K. J.; Kang, S. H.; Lee, H. G. \& Chung, Y. G. Olfactory neuroblastoma following treatment for pituitary adenoma. J. Neurooncol., 90(2):237-41, 2008.

Tamase, A.; Nakada, M.; Hasegawa, M.; Shima, H. \& Yamashita, J. Recurrent intracranial esthesioneuroblastoma outside the initial field of radiation with progressive dural and intra-orbital invasion. Acta Neurochir. (Wien), 146(2):179-82, 2004.

Thompson, L. D. Olfactory neuroblastoma. Head Neck Pathol., 3(3):252-9, 2009.

Vollrath, M.; Altmannsberger, M.; Weber, K. \& Osborn, M. Chemically induced tumors of rat olfactory epithelium: a model for human esthesioneuroepithelioma. J. Natl. Cancer Inst., 76(6):1205-16, 1986.

Yu, T.; Xu, Y. K.; Li, L.; Jia, F. G.; Duan, G.; Wu, Y. K.; Li, H. Y.; Yang, R. M.; Feng, J.; Ye, X. H. \& Qiu, Y. W. Esthesioneuroblastoma methods of intracranial extension: CT and MR imaging findings. Neuroradiology, 51(12):841-50, 2009.

Correspondence to:

Dr. Ilson Sepúlveda Aguilar

Servicio de Otorrinolaringología, Cabeza y Cuello

Hospital Clínico Regional de Concepción

San Martín n 1436

Concepción

CHILE

E-mail: isepulvedaa@udec.cl isepulvedaguilar@gmail.com

Received: 09-03-2012

Accepted: 18-04-2012 